\title{
In the footsteps of Einstein, Sagan and Barnard: \\ Identifying South Africa's most visible scientists
}

AUTHORS:

Marina Joubert ${ }^{1}$

Lars Guenther ${ }^{1}$

\section{AFFILIATION:}

${ }^{1}$ Centre for Research on

Evaluation, Science and

Technology (CREST),

Stellenbosch University,

Stellenbosch, South Africa

\section{CORRESPONDENCE TO:}

Marina Joubert

\section{EMAIL:}

marinajoubert@sun.ac.za

\section{DATES:}

Received: 03 Feb. 2017

Revised: 17 May 2017

Accepted: 06 July 2017

\section{KEYWORDS:}

public visibility; science communication; scientists and public engagement; science and its publics; science and society

\section{HOW TO CITE:}

Joubert M, Guenther L. In the footsteps of Einstein, Sagan and Barnard: Identifying South Africa's most visible scientists. S Afr J Sci. 2017;113(11/12), Art. \#2017-0033, 9 pages. http://dx.doi.org/10.17159/ sajs.2017/20170033

\section{ARTICLE INCLUDES: \\ $\times$ Supplementary material \\ $\times$ Data set}

\section{FUNDING:}

National Research Foundation (South Africa)
Highly visible scientists are increasingly recognised as influential leaders with a special role to play in making science part of mainstream society. Through consultation with a panel of 45 experts working at the science-media interface, we sought to identify the most visible scientists currently living and working in South Africa. In total, 211 scientists - less than 1\% of the scientific workforce of the country - were identified as visible in the public sphere. The demographic profile and institutional spread of South Africa's visible scientists suggest that more should be done to increase the diversity of scientists who are publicly visible. Although only $8 \%$ of South Africans are white, $78 \%$ of the group of visible scientists were white, and $63 \%$ of the visible scientists were men. Only 17 black women were identified as publicly visible scientists. While visible scientists were identified at 42 different research institutions, more than half of the visible scientists were associated with just four universities. Recent controversies surrounding the two most visible South African scientists identified via this study, and the potential implications for fellow scientists' involvement in public engagement, are briefly discussed.

\section{Significance:}

- This is the first study to identify highly visible scientists in South Africa.

- The study has meaningful policy implications for mobilising scientists towards public science engagement.

- It is an important contribution towards the new public engagement framework of the Department of Science and Technology.

\section{Introduction}

A dominant trend in science over the past century is the move away from a closed system in which scientists worked largely in isolation, to a more transparent system in which scientists leave the proverbial ivory tower to engage with society. ${ }^{1}$ Today, effective communication between scientists and diverse public audiences is recognised as an important characteristic of a modern, democratic knowledge society. ${ }^{2}$ Consequently, the notion that scientists should engage with affected publics and debate the social implications of their work openly has become a central element of the moral economy of modern science. However, in a world where science has become increasingly competitive, contested and politicised ${ }^{3}$, the borders between science and politics are blurring and science is more closely coupled with politics and mass media ${ }^{4}$. As a result, public communication of science has also become a tool to compete for public attention and political support ${ }^{5}$ and scientists' motivation to seek public visibility may be complex and diverse.

The growing participation of scientists in public life has been accompanied by a growth in the presence of scientists in popular culture. ${ }^{6}$ Iconic scientists who have shaped the societal discourse about science include people such as Charles Darwin, who was deemed a master of public relations ${ }^{6}$ and Albert Einstein, Time magazine's person of the last century ${ }^{7}$. Towards the end of the 20th century, people like Stephen Jay Gould, Richard Feynman, Carl Sagan and Jane Goodall rose to fame, while present-day science popularisers such as Richard Dawkins, Stephen Hawking, Neil deGrasse Tyson, Brian Greene and David Attenborough continue to enjoy star status. As science continues to expand, it becomes harder for scientists to be visible in public life and the relative invisibility of scientists has emerged as a major concern.

Scientists' academic visibility within their fields of research depends on scholarly publication and citation rates, but public visibility depends on media exposure ${ }^{8}$, which may result from a combination of academic work and involvement in debates and activities outside science. Scientists' active participation in public science communication (for example, presenting popular talks at schools and science centres) is not sufficient to ensure a high public profile. Public visibility requires an amplification of the individual scientist's views and voice - something that would be virtually impossible to achieve without the strategic use of traditional and digital media platforms. ${ }^{6,9}$ Because of the decisive role of the media in achieving public visibility, we identified the most visible scientists in South Africa with the help of a panel of science-media experts, that is, science writers and researchers in the field of science communication and/or media studies.

The case of Carl Sagan is frequently cited as an example of how a high public profile can detract from a scientific career. It is widely believed that Sagan's nomination to the US National Academy of Sciences was voted down by his peers, because they did not approve of his celebrity status. ${ }^{6}$ Subsequently, scientists' fears that public visibility could penalise them career-wise became known as the 'Sagan effect'. Interestingly, Sagan himself did not perceive that he was penalised by his peers as a result of his high public profile. ${ }^{8}$

Despite lingering ambivalence amongst some scientists about the desirability of achieving a high public profile ${ }^{10}$, media interactions - leading to public visibility - have become an integral part of the role of being a scientist and are particularly expected of scientists in leadership roles ${ }^{11}$. Because of their ability to spread their ideas, influence decision-makers and promote scientific culture, high-profile scientists are considered by some as the new academic elite ${ }^{6}$ and increasingly recognised as powerful socio-political influencers and opinion leaders who 
have power within and outside the science arena..$^{12}$ Furthermore, highprofile scientists have been shown to outperform their less visible peers in terms of scientific productivity 13,14 and their media visibility may well boost their scientific impact ${ }^{15,16}$. That is why we had the goal of identifying and locating the most visible scientists in South Africa, with a special focus on their population group, gender, age, employment sector and research fields. This approach is beneficial in terms of identifying what kind of scientists become publicly visible in South Africa and testing whether the publicly visible scientists, as identified in the current study, are representative of the broad South African society. Furthermore, the study has the potential to generate recommendations for increasing the visibility of scientists in South African society.

While the scientific community may have become more accepting of public visibility, some scientists remain concerned about the potentially damaging effects of a high public profile on their scientific reputations. ${ }^{10,17}$ Their concerns are exacerbated by apprehensions about the risks presented by social media. ${ }^{18}$ Furthermore, the rise of public relations approaches in institutional science communication ${ }^{19}$ has resulted in some criticism of the efforts of some institutions and scientists to gain attention for their work ${ }^{5}$. The inevitable tensions between increasing expectations to engage with public audiences and lingering reservations about the potential consequences of doing so, sustain scientists' ambivalence about public visibility. ${ }^{10}$ Given these conflicting prospects in terms of public visibility, it becomes even more important to understand how scientists themselves experience and respond to opportunities and demands to communicate publicly about their research.

\section{The South African context for public science communication}

During the Portuguese colonial rule in Brazil from the 16th to 18th centuries, science was typically suppressed and only the rulers had access to scientific knowledge as a consequence of their links with Europe.$^{20}$ This was also the case during British colonial rule in South Africa (1795-1910). The country's science system continued to serve mostly its white population and government interests ${ }^{21}$ during the racially segregated apartheid regime (1948-1994), thereby continuing to isolate the majority of the country's citizens from science and suppressing the communication of scientific ideas ${ }^{22}$. Despite international isolation, boycotts, sanctions and travel restrictions during the apartheid years, the South African science base continued to strengthen and the country developed advanced facilities and expertise in fields such as geology, mining, energy, nuclear science, space science and military science, as well as in agriculture and veterinary sciences. ${ }^{23}$

During the apartheid years, only one South African scientist became a household name locally and abroad: Christiaan Barnard. Christiaan Barnard (1922-2001) shot to global fame after he performed the first human-to-human heart transplant in Cape Town on 3 December 1967. Barnard's article describing the surgery was published within 4 weeks of the event ${ }^{24}$ and became one of the most cited articles in the field of cardiovascular medicine ${ }^{25}$. The dramatic nature of this medical milestone and the subsequent events captured the attention of the world and they were front page news for some time. It is likely that Barnard's youth and charisma enticed ongoing media attention, but it has also been suggested that politicians exploited him to improve South Africa's image at a time when the country was politically and socially isolated. ${ }^{25}$

South Africa has delivered other celebrated academics who were highly regarded within science, but they - arguably - never became household names. Names that come to mind include the visionary veterinary researcher Sir Arnold Theiler and the eminent and much-loved palaeoanthropologist Phillip V. Tobias.

The arrival of democracy in 1994 changed South African society fundamentally. In this new dispensation, science and technology were seen as essential instruments for economic growth and social development. ${ }^{26}$ In addition to a new political and social landscape, there was an expectation that science should also be democratised. The science base at the time of transition to democracy was based on only about $10 \%$ of the population.
The country now had a much larger pool of talent on which to draw, but developing this expertise would require extensive educational reform, as well as intensive teaching and mentoring in order to correct the injustices and imbalances of the past. ${ }^{27}$ Consequently, new government policy emphasises the need for more effective engagement between science and society, and the government is urging the country's scientists to become actively and visibly involved in public science communication in order to make their work accessible, meaningful and relevant to all South Africans, in particular historically disadvantaged communities. ${ }^{28}$ These calls are in line with increasing demands on scientists to engage pro-actively with a wide range of public and policy audiences, including entering into meaningful dialogue with society about uncertainty in science and the ethical implications of cutting-edge research. ${ }^{29}$

The Year of Science and Technology 1998 - or 'Yeast 98' as it was popularly known - was the first nationwide science communication initiative in democratic South Africa. This public communication campaign consisted of exhibitions, popular science talks and interactive workshops that moved around the country. Subsequently, the government has organised annual science and technology weeks and contributed funding to various science centres and science festivals. In 2002, the Department of Science and Technology established the South African Agency for Science and Technology Advancement (SAASTA) as a business unit of the National Research Foundation, with the specific aim to advance public awareness, appreciation and engagement of science, engineering and technology in South Africa. Early in 2015 , the Department of Science and Technology announced a new strategic framework for public science engagement ${ }^{28}$, which is intended to coordinate and encourage science promotion, communication and engagement activities at a national level. The stated objectives of the framework blend promotional aims (popularising science to awaken interest and global profiling of South African science) and engagement goals (developing a critical public that participates actively in the national discourse on science and technology).

Achieving the government's ambitious public engagement goals will require not only the support of South Africa's institutional science system, but also the participation of as many individual scientists as possible. However, in order to design effective strategies and support structures to mobilise scientists in terms of public science communication, we must understand the motivations and barriers that influence their willingness and ability to get involved.

Several scholars have emphasised the significance of understanding how scientists themselves perceive public communication and their roles in public life as a first step in developing effective public science engagement strategies. ${ }^{30,31}$ While the public communication of science, including the factors that influence scientists in terms of their communication with lay audiences, has attracted considerable research interest over the last few decades, local studies were mostly limited to explorations of public science literacy and attitudes to science. ${ }^{32}$ Only two studies investigated interactions between South African scientists and journalists ${ }^{33,34}$ and both highlighted gaps in understanding and skills deficits on the sides of both journalists and scientists.

Currently, we still know very little about the motivations and barriers that influence South African scientists' public communication behaviour, and how they perceive the benefits and risks associated with a high public profile. It is hoped that future research will help to inform new policies and support structures aimed at encouraging and incentivising scientists towards more visible participation in public life. The current study is a first step towards achieving this goal. Consequently, the research question steering the current study is: Who and where are the visible scientists in South Africa?

Background information about these scientists - including their demographic profiles, fields of research and institutional affiliations - provides new perspectives on the factors that determine scientists' visibility in the public sphere within South Africa's unique science arena and socio-political context. 


\section{Methodology}

For the purpose of this study, public science communication is defined as the communication of scientific information - by scientists - to people not involved with research in the same field. Visible scientists were identified as those scientists who were considered to be known to the South African public - at least to some extent - by one or more members of a panel of individuals working at the interface between science and the media.

A number of factors - including age $\mathrm{e}^{35}$, gender ${ }^{36}$, position ${ }^{37}$, discipline ${ }^{38}$ and organisational culture ${ }^{39}$ - have been shown to influence if and how scientists communicate with public audiences. As such, the aim of the current study was to identify publicly visible scientists in South Africa, along with relevant background information about them that might help explain their public visibility.

After considering various options for identifying publicly visible scientists (such as selecting recipients of science engagement awards, choosing scientists based on the frequency of media appearances or doing a public opinion survey), asking a panel of science-media experts (similar to the approach followed by Rae Goodell in her landmark study of visible scientists in $1975^{\circ}$ ) was deemed to be the most feasible and effective. Goodell points out that using a panel of respondents - each with their own experiences of scientists interacting with the public - allows the researcher to draw indirectly on a number of indicators of visibility.

Based on the first authors' experience of 25 years in the South African science communication arena, panel members were selected to represent local expertise in science journalism, popular science writing, public science engagement, and research in the field of science communication. To avoid bias in favour of visible scientists at a specific research organisation, no corporate communicators associated with a specific institution (university or science council) were included in the panel; this exclusion was not applied to researchers based at institutions.

Potential panel members were contacted via email (with reminders via email and social media) in order to ask them to help identify scientists who they perceived to have achieved some level of public visibility in South Africa. In line with the approach used by Goodell ${ }^{8}$, the request was kept brief and simple; respondents were asked to be liberal in their definition of a scientist. Following a short introduction to the research project, one simple question was asked: 'Please write down the names of about five to ten scientists - currently living and working in South Africa - who you consider to be publicly visible.' Respondents were asked to name a maximum of 10 scientists for two reasons: (1) to ensure that it would not be a time-consuming task, and also (2) to encourage them to submit names of only the scientists who were well known in the public sphere.

Of the 63 experts who were approached, $45(71 \%)$ responded to the request by sending names of scientists who they perceived to be publicly visible in South Africa. Of these 45 respondents, 41 are white ( 4 are black) and 29 are women (16 are men). The industry sectors represented by panel members are reflected in Table 1.

Correspondence took place during November and December 2016. From the responses, names of South African born scientists who were no longer in the country at the time of the study (such as Elon Musk and Mark Shuttleworth) were deleted, as were the names of deceased scientists (such as Phillip Tobias). From the names provided by the respondents, further desktop research was undertaken to determine the population group, gender and research fields of the group of 211 scientists identified as publicly visible, as well as to determine the age profile of the 'top 18' scientists (i.e. the scientists mentioned most often by the respondents).

Ethical clearance for this study was obtained from the Research Ethics Committee: Human Research (Humanities) at Stellenbosch University (reference number SU-HSD-004069).

\section{Results}

\section{The number of visible scientists in South Africa}

According to 2014/2015 statistics, South Africa has 25300 researchers (excluding doctoral students and postdoctoral fellows at higher education institutions) ${ }^{40}$ Researchers are defined as professionals engaged in the conception or creation of new knowledge, products, processes, methods and systems, and in the management of the projects concerned. ${ }^{40}$ (The terms 'researcher' and 'scientist' are used interchangeably in this article.) Of these 25300 researchers who make up the scientific workforce, only 211 scientists (less than 1\%) were identified as being publicly visible by the 45 respondents who constituted the media panel for this study. In total, 367 names were suggested, representing 211 individuals once duplicate mentions were removed. Given that the maximum number of names expected if each respondent listed 10 unique names would be 450 , the list of 367 names represented $82 \%$ of the expected maximum.

Only 46 of the 211 scientists were mentioned by two or more panel members. This means that 165 scientists (78\% of the total group) were mentioned by only one person on the media panel, suggesting that most of the visible scientists identified in the current study are not genuinely publicly visible, but rather known as a result of limited media exposure, with possibly only one journalist. Professor Lee Berger - a palaeoanthropologist at the University of the Witwatersrand - emerged as the most visible scientist in South Africa with 27 mentions.

The 'top 18' - i.e. scientists who were mentioned by four or more panel members - are listed in Table 2, along with their research fields and institutional affiliations. This group of 18 scientists can therefore be defined as having achieved a significant level of public visibility.

\section{South Africa's visible scientists per population group}

While white scientists constitute $59 \%$ of the current scientific workforce of the country ${ }^{40}, 164$ of the visible scientists in this study (or $78 \%$ of the visible group) were white. Black researchers (consisting of African, coloured and Indian researchers) constitute $42 \%$ of the scientific workforce. ${ }^{40}$ Only 47 black researchers (22\% of the group of 211 visible researchers) were identified as being publicly visible.

The 164 white scientists identified as publicly visible represent $1 \%$ of the white scientists in South Africa, while the 47 black scientists represent only $0.4 \%$ of the black scientists in the country. The 18 most visible scientists (Table 2) are made up of 11 white and 7 black scientists.

\section{The gender balance of South Africa's visible scientists}

The male:female ratio in South Africa's scientific workforce ${ }^{40}$ is $56 \%$ male to $44 \%$ female. Men outnumber women in the scientific workforce, but were even more dominant amongst the group of 211 visible scientists identified in the current study, with 133 (63\%) men and 78 $(37 \%)$ women. Similarly, $11(61 \%)$ of the 18 most visible scientists (as listed in Table 2) were men. There were only 17 black women ( $8 \%$ of the visible group) amongst the visible scientists.

\section{Age and seniority profile of the most visible scientists}

All of the most visible scientists identified in this study (i.e. the top 18 scientists mentioned by four or more of the respondents) were born between 1947 and 1971, meaning that - on their birthday in 2016 - their ages ranged between 45 and 69 years, with an average age of 52 years. Only two people in this group of scientists were younger than 50 years at the time.

In terms of seniority, 14 of the 18 most visible scientists (77\%) were full professors, while 1 (who was also the youngest in the group) was an associate professor. Two of the remaining three scientists held a PhD, but were not employed in the higher education sector. Only one of the top 18 most visible scientists did not have a PhD. 
Table 1: $\quad$ Science-media panel respondents $(n=45)$

\begin{tabular}{|c|c|c|}
\hline Name and surname & Affiliation & Industry sector \\
\hline Duncan Alfreds & Media24 & Online (general news website) \\
\hline Sheree Bega & Saturday Star & Print media (newspaper) \\
\hline Sue Blaine & Financial Mail & Print media (magazine) \\
\hline Nana Boaduo & National Research Foundation & Science communication (agency) \\
\hline Val Boje & Pretoria News & Print media (newspaper) \\
\hline Elsabé Brits & Netwerk24 & Print and online news \\
\hline Tony Carnie & The Mercury & Print media (newspaper) \\
\hline Katharine Child & The Times & Print media (newspaper) \\
\hline Lesley Cowling & University of the Witwatersrand & Research \\
\hline Marize de Klerk & Video News 247 & Online (video news) \\
\hline Izak du Plessis & SABC & Broadcast (radio) \\
\hline Harry Dugmore & Rhodes University & Research \\
\hline Engela Duvenage & Freelance & Science communicator \\
\hline Alex Eliseev & EWN & Broadcast (radio) \\
\hline Amelia Genis & Landbouweekblad & Print media (magazine) \\
\hline Yolandi Groenewald & City Press & Print media (newspaper) \\
\hline Daryl Ilbury & Freelance & Science communicator \\
\hline Natasha Joseph & The Conversation Africa & Online (research news and opinion) \\
\hline Tamar Kahn & Business Day & Print media (newspaper) \\
\hline Lia Labuschagne & Freelance & Science communicator \\
\hline Ruda Landman & Freelance & Freelance (television) \\
\hline Steven Lang & Freelance & Freelance (print media) \\
\hline Tony Lelliot & University of the Witwatersrand & Research \\
\hline Janice Limson & Rhodes University & Research \\
\hline Stephan Lombard & Cape Talk Radio & Broadcast (radio) \\
\hline Munyaradzi Makoni & Freelance & Online and print media \\
\hline Mia Malan & Mail \& Guardian & Print media (newspaper) \\
\hline Izak Minnaar & SABC & Online (news) \\
\hline Anina Mumm & ScienceLink & Science communicator \\
\hline Thabiso Nkone & National Research Foundation & Research management \\
\hline Linda Nordling & Freelance & Print media \\
\hline Joanne Riley & SAASTA & Research management \\
\hline Freek Robinson & kykNET & Broadcast (television) \\
\hline Ina Roos & Freelance & Print media \\
\hline Marika Sboros & Freelance & Print media \\
\hline Elna Schütz & The Wits Radio Academy & Broadcast (radio) \\
\hline Mandi Smallhorne & Freelance & Print and online media \\
\hline Lynne Smit & Hippo Communications & Science communicator \\
\hline Elise Tempelhoff & Beeld & Print media (newspaper) \\
\hline Anso Thom & Health-e/Section27 & Online (health news) \\
\hline Irma Venter & Engineering News & Print media (magazine) \\
\hline Derek Watts & Carte Blanche & Broadcast (television) \\
\hline Mandy Wiener & Freelance & Broadcast (radio) \\
\hline Sarah Wild & Freelance & Print and online media \\
\hline John Yeld & Freelance & Print media \\
\hline
\end{tabular}

Respondents were advised that their names would be published unless they objected; there were no objections. 
Table 2: Publicly visible scientists mentioned by four or more members of the science-media panel

\begin{tabular}{|c|c|c|c|}
\hline Scientist & Research field & Institution & Mentions \\
\hline Professor Lee Berger & Natural sciences (palaeoanthropology) & $\begin{array}{l}\text { University of the Witwatersrand and National Geographic } \\
\text { explorer-in-residence }\end{array}$ & 27 \\
\hline Professor Tim Noakes & Health sciences (exercise, sports science, nutrition) & $\begin{array}{l}\text { University of Cape Town (Emeritus Professor) and The } \\
\text { Noakes Foundation }\end{array}$ & 14 \\
\hline Professor Glenda Gray & Health sciences (perinatal HIV care) & Medical Research Council & 12 \\
\hline Professor Bob Scholes & Natural sciences (ecology) & University of the Witwatersrand & 10 \\
\hline Professor Salim Abdool-Karim & Health sciences (epidemiology and infectious diseases) & $\begin{array}{l}\text { University of KwaZulu-Natal and Centre for the AIDS } \\
\text { Programme of Research in South Africa (CAPRISA) }\end{array}$ & 10 \\
\hline Professor Anusuya Chinsamy-Turan & Natural sciences (palaeobiology) & University of Cape Town & 8 \\
\hline Professor Himla Soodyall & $\begin{array}{l}\text { Natural sciences (population genetics and molecular } \\
\text { anthropology) }\end{array}$ & $\begin{array}{l}\text { University of the Witwatersrand and National Health } \\
\text { Laboratory Service }\end{array}$ & 8 \\
\hline Doctor Bernie Fanaroff & Physical sciences (astronomy/astrophysics) & $\begin{array}{l}\text { South African Square Kilometre Array Project (National } \\
\text { Research Foundation) }\end{array}$ & 7 \\
\hline Professor Anthony Turton & Natural sciences (water resource management) & University of the Free State and TouchStone Resources & 6 \\
\hline Professor Linda-Gail Bekker & $\begin{array}{l}\text { Health sciences (HIV, infectious disease and molecular } \\
\text { medicine) }\end{array}$ & University of Cape Town (Desmond Tutu HIV Centre) & 5 \\
\hline Professor Tebello Nyokong & $\begin{array}{l}\text { Physical sciences (medicinal chemistry and } \\
\text { nanotechnology) }\end{array}$ & Rhodes University & 5 \\
\hline Dave Pepler & Natural sciences (ecology and conservation) & Academy for Environmental Leadership & 4 \\
\hline Professor Bongani Mayosi & Health sciences (dean of faculty) & University of Cape Town & 4 \\
\hline Professor Bruce Rubidge & Natural sciences (palaeontology) & University of the Witwatersrand & 4 \\
\hline Professor Kelly Chibale & $\begin{array}{l}\text { Physical sciences (drug discovery and medicinal } \\
\text { chemistry) }\end{array}$ & University of Cape Town & 4 \\
\hline Professor Francis Thackeray & Natural sciences (palaeontology) & University of the Witwatersrand & 4 \\
\hline Professor Jill Farrant & Natural sciences (drought tolerance in plants) & University of Cape Town & 4 \\
\hline Professor Nox Makunga & Natural sciences (medicinal plants) & Stellenbosch University & 4 \\
\hline
\end{tabular}

\section{South Africa's visible scientists per employment sector}

A breakdown of the institutions at which the visible scientists work (Table 3) revealed that just more than half $(109$, or $52 \%$ ) of the 211 publicly visible scientists identified in this study were working at just four universities. A total of 157 out of 211 (74\%) were employed at just 10 institutions. The University of Cape Town was home to most of the high-profile scientists in South Africa, followed by the University of the Witwatersrand, University of Pretoria and Stellenbosch University. The rest of the visible scientists were spread over 42 other research institutions, of which 27 institutions were represented by only one scientist. Notably, there are many more research organisations (science councils and universities) in the country from which not a single scientist was identified as being publicly visible.

In total, 160 of the 211 visible scientists $(76 \%)$ in the country were employed in the higher education sector, with $22(10 \%)$ employed in science councils and $12(6 \%)$ in the not-for-profit sector. There were relatively few visible scientists in industry (only 7 , or $3 \%$ ), and even fewer (only 5 , or $2 \%$ ) in government. Five of the visible scientists were retired and no longer affiliated to a specific institution.
Table 3: The top ten South African institutions in terms of the number of publicly visible scientists

\begin{tabular}{l|c}
\hline \hline \multicolumn{1}{c|}{ Institution } & $\begin{array}{c}\text { Number of visible } \\
\text { scientists }\end{array}$ \\
\hline University of Cape Town & 37 \\
\hline University of the Witwatersrand & 34 \\
\hline University of Pretoria & 20 \\
\hline Stellenbosch University & 17 \\
\hline Rhodes University & 9 \\
\hline University of KwaZulu-Natal & 9 \\
\hline University of Johannesburg & 9 \\
\hline $\begin{array}{l}\text { National Research Foundation (Square Kilometre Array } \\
\text { South Africa and the South African Astronomical } \\
\text { Observatory) }\end{array}$ & 7 \\
\hline North-West University & 7 \\
\hline University of the Free State & 7 \\
\hline
\end{tabular}




\begin{tabular}{|c|c|}
\hline Broad research field & $\begin{array}{l}\text { Number of } \\
\text { visible scientists }\end{array}$ \\
\hline $\begin{array}{l}\text { Natural, biological and agricultural sciences (including animal and plant studies, microbiology, conservation, marine biology, biotechnology, } \\
\text { genetics, agriculture, food security, palaeontology and palaeoanthropology) }\end{array}$ & 64 \\
\hline Social sciences, arts and humanities (including education, communication, media studies, history, economics, political science, law) & 50 \\
\hline Health sciences (including HIV/Aids, disease, public health, nutrition, sports science and private medical practice) & 38 \\
\hline Physical sciences (including mathematics, chemistry, physics, nanotechnology, astronomy, astrophysics and space science) & 31 \\
\hline Environmental sciences (including climate sciences, earth sciences, waste, water and pollution) & 16 \\
\hline Engineering (including energy, materials science, chemical engineering, infrastructure, electronics) & 12 \\
\hline
\end{tabular}

\section{South Africa's visible scientists per broad research field}

Table 4 provides a breakdown of the visible scientists in South Africa according to broad research field. Most of the visible researchers in South Africa, as identified in this study, worked in the natural sciences and it is interesting to note that this group included eight researchers in the field of palaeontology. The combined disciplines of social sciences, humanities and arts represented the second biggest group of visible scientists, followed by health sciences, physical sciences and environmental sciences. Only 12 engineers (6\%) were identified as publicly visible.

\section{Discussion}

\section{Too few black and women scientists in the public eye}

Only 211 of the 25300 South African researchers ${ }^{40}$ - less than $1 \%$ were identified as being publically visible within South Africa. Within this group, black and female scientists were proportionally underrepresented.

Black scientists make up $42 \%$ of the researchers in South Africa, but only $33 \%$ of the visible scientists in this study. Similarly, women constitute $44 \%$ of the research workforce, but only $34 \%$ of the visible group.

When these figures are seen in the context of the overall population demographics of the country, the underrepresentation of black and female scientists is even more prominent. According to recent population estimates from Statistics South Africa ${ }^{41}$, the total South African population stands at 55.9 million people, of whom $92 \%$ are black and $51 \%$ are female. White people constitute only $8 \%$ of the overall South African population, but $78 \%$ of the visible scientists in this study (164 out of 211) were white.

Given the political past of South Africa, one could argue that it is encouraging that there are 47 black scientists (including 17 women) deemed to be publicly visible at the present moment in South Africa. A deeper understanding of their experiences of public communication of science could reveal the best way forward to increase the participation of black scientists in public communication about their research.

In terms of the effect of gender on careers in science, the dominance of men at higher levels in the academic hierarchy is well documented, as is the evidence for a general structural bias against women in science ${ }^{42}$, while female scientists in Africa face a particularly dire situation ${ }^{43}$. Women also face particular barriers in terms of getting involved in public science engagement and may even be advised to avoid these activities or risk not being taken seriously by their male peers. ${ }^{44}$ There is also evidence that active involvement in public engagement is generally valued in a man's portfolio, but criticised when part of a woman's portfolio. ${ }^{45}$ Given the persistent stigmatising of women who are actively involved in public science communication, it is no surprise that some female scientists avoid or downplay personal involvement in these activities and understandable that nearly two thirds (133 out of 211) of the visible scientists identified in this study were men. In contrast, some studies show that, despite the normative sanction from their peers, female scientists are significantly more involved in reaching out to external audiences compared with their male colleagues. ${ }^{31}$

The dominance of male scientists in public life is not unique to South Africa. For example, there were only two women - Margaret Mead and Jane Goodall - in the list of the 20 most visible scientists identified by Goodell ${ }^{8}$. Similarly, Fahy ${ }^{6}$ included only one woman - Susan Greenfield in his chronicle of the lives of high-profile scientists of today.

However, in South Africa, increasing the gender and racial diversity of the science workforce (i.e. attracting young women and black youth to research careers), is an important objective of public science communication. Publicly visible black and female scientists can act as role models for young people and help to shatter the racial and gender stereotypes in science. It is therefore important to understand how local black and female scientists respond to demands for increased public science engagement, and what specific factors encourage or constrain their involvement.

\section{Public visibility increases with seniority}

Research has shown that journalists often prefer to interview scientists who are more senior and likely to be in influential positions and regarded as leaders in their fields, and therefore it takes time for scientists to achieve public visibility; also senior scientists are more likely to engage with the public and be better able to deal with the potentially negative responses that may result from public visibility from time to time. , $35,38,46^{2}$ This contention is also evident in the age profile of the 18 most visible scientists identified in this study who were between 45 and 69 years old, with an average age of 52 (and only two researchers younger than 50 ). These findings are in line with the higher levels of public communication involvement of more senior researchers who have been demonstrated in, for example, Switzerland ${ }^{36}$ and Argentina ${ }^{37}$. It has also been suggested that scientists should earn a scientific reputation before venturing out into the public arena. ${ }^{8} \mathrm{It}$ is therefore not surprising that 14 of the 18 most visible scientists were full professors, which allows them the credibility and protection of a high standing in the academic world.

\section{The effect of organisational culture on public visibility}

In today's global research arena in which universities increasingly have to justify research spending and compete for the attention of funders and partners, institutions are looking for ways to demonstrate their social relevance and impact via the public engagement activities of their researchers. Consequently, organisational culture, policies, norms, reward structures, institutional expectations and the quality and availability of communication support services have been shown to influence public visibility of researchers. ${ }^{47,48}$ Scientists also strive for recognition within their institutions and may pursue public and media visibility in order to establish and boost their own reputations. ${ }^{19}$ While organisational culture can support scientists' efforts to engage external audiences, institutional constraints mean that scientists may also be penalised for their efforts to become publicly visible. ${ }^{1,39}$ 
In this context, it is interesting to note that more than half of the 211 publicly visible scientists identified via this study were employed at just four South African universities. These universities - Cape Town, Witwatersrand, Pretoria and Stellenbosch - are all research-intensive universities ranked amongst the best higher education institutions in the country. ${ }^{49}$ It is reasonable to assume that the organisational culture and policies, as well as the public relations support, that are available at these top universities, play a role in helping the scientists who work there to achieve and sustain higher public profiles. Apart from these four universities, the rest of the visible scientists in the country were thinly spread across the science sector, with many universities and other research organisations featuring just one publicly visible scientist. There were also several universities and science councils, as well as national and provincial government departments, missing from the list of institutions hosting visible scientists, meaning that none of the 45 media panel members mentioned a visible scientist at these institutions.

\section{The effect of discipline on public visibility}

There are many reasons why scientists' efforts to communicate with public audiences about their research may be affected by their own field of research. For example, the public tends to be more interested in topics that are close to everyday life and resonate with human interest. ${ }^{8}$ Also, the esoteric nature of natural and physical sciences, and the highly codified language used in these fields, make it challenging to present new ideas to lay audiences. ${ }^{13,50}$ Researchers working in some fields may perceive a strong moral duty to make their work publicly accessible, while other disciplines are governed by more restrictive norms. ${ }^{31}$

The number of visible South African scientists per broad scientific field, as identified in the current study, were in line with these findings and also reflected the scientific opportunities and priorities of the country. For example, given the country's rich biodiversity ${ }^{51}$ and unique fossil heritage ${ }^{52}$, it is not surprising that there were many biologists and palaeontologists amongst the visible scientists (Table 4). Similarly, given the local health challenges ${ }^{53}$, it is understandable that HIV, tuberculosis and public health dominate as areas of expertise amongst the publicly visible health researchers. The importance and relevance of social scientists in a developing country context is underlined by the fact that nearly a quarter of the publicly visible scientists were social science scholars working on topics such as politics, economics, gender studies, communication, criminology, violence, trauma and reconciliation.

Amongst the 18 most visible scientists in the country, more than half (10) were from the natural sciences (of which 4 were in fields related to palaeontology), 5 were in health sciences, and 3 in physical sciences. Notably, there were no social scientists or engineers in this group of the most visible scientists. This finding indicates that scientists in these fields have therefore not achieved a similar level of visibility compared with the best-known experts in the country in fields such as palaeontology, climate change and HIV/Aids research.

\section{Berger and Noakes - blending science celebrity and notoriety}

Goodell ${ }^{8}$ reflects on the discomfort that some scientists experience when peers or colleagues attain high public profiles, including that they are sometimes seen as irritating and even hazardous because of their tendency to break old rules of protocol in the scientific profession, question old ethics and defy old standards of conduct. She adds that scientists are often concerned that high-profile colleagues will mislead the public when they speak outside their areas of expertise - as they often do. These observations about visible scientists - and the ways in which other scientists respond - are reminiscent of recent controversies that have surrounded the two most visible scientists identified in this study - Lee Berger and Tim Noakes.

There is little doubt that controversy is a catalyst for public visibility ${ }^{8}$ and that visibility in the mass media feeds further visibility via the feedback loops of media attention ${ }^{54}$ and reciprocal intensification ${ }^{39}$. Lee Berger and Tim Noakes have both experienced considerable public and peer criticism that has certainly boosted their public visibility. Both of them are acclaimed, senior scientists: Lee Berger is rated as an 'internationally acclaimed researcher', and Tim Noakes as a 'leading international researcher' according to the evaluation and rating system of the National Research Foundation (as at 14 December 2016). Seniority and status have been shown to help scientists cope with critical storms that may result from high media visibility. 8,46

When, towards the end of 2015 , Lee Berger went public with his theory that Homo naledi was a human ancestor that in all likelihood deliberately buried its dead ${ }^{55}$, the discovery became mired in controversy and elicited societal and scientific criticism ${ }^{56}$. Amongst other things, Berger was accused of rushing his research to please the media ${ }^{57}$ and even of promoting racist pseudoscience intent on showing that Africans were sub-human ${ }^{58}$. In a press conference on 9 May 2017, Berger and his research team not only announced that many more of these fossils have been discovered, but also dated them and presented further claims that the species could have shared cognitive traits with modern humans, as their hands were capable of making and manipulating tools.

Tim Noakes' advocacy in favour of a diet low in carbohydrates and high in fat ${ }^{59}$ has resulted in an outright diet war between passionate supporters, mostly members of the public, and fierce critics, who were mostly in the scientific community. Fellow scientists have challenged the scientific basis of the low-carbohydrate-high-fat diet ${ }^{60}$, while colleagues at the University of Cape Town have accused him of making outrageous and unproven claims and have distanced themselves from his dietary recommendations ${ }^{61}$.

Two South African science journalists - Sarah Wild and Alex Eliseev weighed in on the Berger and Noakes controversies, and how they have played out in the public sphere. Wild ${ }^{62}$ claims that so-called 'rock star scientists' - such as Berger and Noakes - are populists and that their style of communication - oversimplifications, appeals to emotions and anecdotes - threatens public trust in science (should they later be proven wrong). Eliseev ${ }^{63}$ disagrees; he posits that to get people interested in science, you have no choice but to simplify. Furthermore, scientists routinely disagree and will debate fossil finds and diets for years to come. Eliseev describes Berger as one of those rare scientists with flare and personality - the X-factor - with a talent to make science exciting and entertaining. He sees no problem with Berger's ability to use the media to his advantage, adding that it helps to fund research and has other positive spin-offs for society.

Like Berger and Noakes, many high-profile scientists have on occasion experienced damaging criticism from peers. While their strong track record may help them to weather these storms, they are not oblivious to these attacks on their credibility, and often fear the criticism from their peers. ${ }^{8}$ This effect is evident in responses from Noakes after he was found not guilty of unprofessional conduct, following a drawn out disciplinary hearing by the Health Professions Council of South Africa. Commenting on the letter by University of Cape Town academics, Noakes told a journalist ${ }^{64}$ : "What that letter did was to isolate me from my university and my faculty; from the university unit that I had started and from the Sports Science Institute of South Africa which I had also helped found'. About the drawn-out hearing itself, he said: 'My wife and I simply could not escape it - we spoke about it endlessly, wondering why it had come about; how we might have avoided it; how heartless were the people who were driving it and we even wondered at times whether our lives might be in danger.'

Controversies like these - characterised by an intense focus on a specific individual - may discourage other South African scientists from going public with their research findings. It is therefore important to understand how visible scientists cope with and respond to controversy, and to discover what lessons other scientists can learn from their experiences.

\section{Study limitations and suggested future research}

The present study has important limitations. To identify visible scientists in South Africa, only experts working at the science-media interface were considered, only 45 of them responded to the request, and the respondent group was predominantly white. In addition, these experts were asked to name only between 5 and 10 scientists. There might be other respondent groups to consider that could extend the number of 
visible scientists in South Africa. Furthermore, only names of visible scientists were gathered; the background data were sourced from desktop research. These findings lead to interesting new research questions. For instance, it would also be prudent to investigate the communication culture and support structures at the four universities that are home to more than half of the publicly visible scientists identified in this study, in order to elucidate the successful communication drivers that could possibly be adopted by other research organisations across the country. A better understanding of the communication behaviour and experiences of high-profile scientists who have endured intense public and peer scrutiny - as is the case with the two most visible scientists in this study - will further aid our understanding of the factors that influence and shape the interaction between scientists and their diverse publics in a country like South Africa.

\section{Conclusion}

Despite the above-mentioned limitations, the present study has important implications. Given the science transformation goals of the country - especially in terms of attracting more black youth into science and demonstrating the social relevance of research - it is of importance to increase the visibility of black scientists and to raise the profile of black intellectuals in the country. To achieve these goals, a new generation of black scientists must be equipped with the confidence and skills to become publicly visible via mass media platforms. Similarly, more female scientists must be mobilised, motivated and incentivised to communicate and engage with the broad South African society. Therefore, in order to reach the goals outlined in its ambitious public engagement framework, the South African government will need to broaden the base of scientists who become visible in the public eye. Investigations into the profiles and experiences of high-profile scientists highlight the factors that influence public visibility and help to inform future policies designed to support public science communication.

\section{Acknowledgements}

We thank the National Research Foundation of South Africa for funding (grant number 93097).

\section{Authors' contributions}

M.J. was responsible for the research. M.J. and L.G. collaborated on the processing, presentation and discussion of the findings.

\section{References}

1. Bucchi M, Trench B. Science communication research: themes and challenges. In: Bucchi M, Trench B, editors. Routledge handbook of public communication of science and technology. New York: Routledge; 2014. p. 1-14.

2. Horst MA. Field of expertise, the organization, or science itself? Scientists' perception of representing research in public communication. Sci Commun. 2013;35(6):758-779. http://dx.doi.org/10.1177/1075547013487513

3. Scheufele DA. Science communication as political communication. Proc Natl Acad Sci USA. 2014;111(Suppl. 4):13585-13592. http://dx.doi.org/ doi:10.1073/pnas.1317516111

4. Weingart P. The moment of truth for science. EMBO Rep. 2002;3(8):703706. http://dx.doi.org/10.1093/embo-reports/kvf165

5. Weingart P, Guenther L. Science communication and the issue of trust. JCOM. 2016;15(5), C01, 11 pages.

6. Fahy D. The new celebrity scientists. New York: Rowman \& Littlefield; 2014.

7. Golden F. Albert Einstein: Person of the century. Time Magazine. 1999;154(27):34-37.

8. Goodell RS. The visible scientists [dissertation]. New York: Stanford University; 1975

9. Fahy D, Lewenstein B. Scientists in popular culture: The making of celebrities. In: Bucchi M, Trench B, editors. Routledge handbook of public communication of science and technology. New York: Routledge; 2014. p. 83-96.
10. Rödder $S$. The ambivalence of visible scientists. In: Rödder S, Franzen M, Weingart P, editors. The sciences' media connection-public communication and its repercussions. Dordrecht: Springer; 2012. p. 155-178.

11. Peters HP. Gap between science and media revisited: Scientists as public communicators. Proc Natl Acad Sci USA. 2013;110(Suppl. 3):1410214109. http://dx.doi.org/doi:10.1073/pnas.1212745110

12. Baron N. Stand up for science. Nature. 2010;468:1032-1033. http://dx.doi. org/10.1038/4681032a

13. Bentley P, Kyvik S. Academic staff and public communication: A survey of popular science publishing across 13 countries. Public Underst Sci. 2011;20(1):48-63. https://doi.org/10.1177/0963662510384461

14. Jensen P. A statistical picture of popularization activities and their evolutions in France. Public Underst Sci. 2011;20(1):26-36. http://dx.doi. org/10.1177/0963662510383632

15. Liang X, Su LY, Yeo SK, Scheufele DA, Brossard D, Xenos M, et al. Building buzz: (Scientists) communicating science in new media environments. Journalism Mass Comm. 2014;91(4):772-791. http://dx.doi. org/10.1177/1077699014550092

16. Phillips DP, Kanter EJ, Bednarczyk B, Tastad PL. Importance of the lay press in the transmission of medical knowledge to the scientific community. N Engl J Med. 1991;325:1180-1183. http://dx.doi.org/10.1056/ NEJM199110173251620

17. Casini S, Nerisini F. Behind closed doors: Scientists' and science communicators' discourses on science in society. A study across European research institutions. Technoscienza. 2012;3(2):37-62.

18. Mandavilli A. Trial by Twitter. Nature. 2011;469:268-269. http://dx.doi. org/10.1038/469286a

19. Marcinkowski F, Kohring $M$. The changing rationale of science communication : A challenge to scientific autonomy. JCOM. 2014;13(03), C04, 8 pages.

20. Massarani L, De Castro Moreira I. Science communication in Brazil: A historical review and considerations about the current situation. An Acad Bras Cienc. 2016;88(3):1577-1595. http://dx.doi.org/10.1590/00013765201620150338

21. Pandor N. South African science diplomacy: Fostering global partnerships and advancing the African agenda. Sci Diplomacy. 2012;1(1), 6 pages. http:// www.sciencediplomacy.org/files/south_african_science_diplomacy.pdf

22. Dubow S. A commonwealth of knowledge: Science, sensibility and white South Africa 1820 - 2000. New York: Oxford University Press; 2006.

23. Sooryamoorthy R. Science and scientific collaboration in South Africa: Apartheid and after. Scientometrics. 2010;84(2):373-390. http://dx.doi. org/10.1007/s11192-009-0106-y

24. Barnard CN. The operation. A human cardiac transplant: An interim report of a successful operation performed at Groote Schuur Hospital, Cape Town. S Afr Med J. 1967;41(48):1271-1274.

25. Brink JG, Hassoulas J. The first human heart transplant and further advances in cardiac transplantation at Groote Schuur Hospital and the University of Cape Town. Cardiovasc J Afr. 2009;20(1):31-35.

26. South African Department of Science and Technology (DST). White paper on science and technology. Pretoria: DST; 1996.

27. Philander SG. How many scientists does South Africa need? S Afr J Sci. 2009;105(5/6):172-173.

28. South African Department of Science and Technology (DST). Science engagement framework. Pretoria: DST; 2014.

29. House of Lords. Science and society. London: House of Lords; 2000.

30. Poliakoff E, Webb TL. What factors predict scientists' intentions to participate in public engagement of science activities? Sci Commun. 2007;29(2):242263. https://doi.org/10.1177/1075547007308009

31. Johnson DR, Ecklund EH, Lincoln AE. Narratives of science outreach in elite contexts of academic science. Sci Commun. 2014;36(1):81-105. https:// doi.org/10.1177/1075547013499142

32. Reddy V, Gastrow M, Juan A, Roberts B. Public attitudes to science in South Africa. S Afr J Sci. 2013;109(1/2), Art. \#1200, 8 pages. http://dx.doi. org/10.1590/sajs.2013/1200 
33. Claassen G. Science and the media in South Africa: Reflecting a 'dirty mirror.' Communicatio. 2011;37(3):351-366. https://doi.org/10.1080/02500167.20 11.622288

34. Gething L. 'Them and us': Scientists and the media - attitudes and experiences. S Afr Med J. 2003;93(3):197-201.

35. Bauer $M$, Jensen $P$. The mobilization of scientists for public engagement. Public Underst Sci. 2011;20(1):3-11. https://doi.org/10.1177/0963662510394457

36. Crettaz von Roten F. Gender differences in scientists' public outreach and engagement activities. Sci Commun. 2011;33(1):52-75. https://doi. org/10.1177/1075547010378658

37. Kreimer P, Levin L, Jensen P. Popularization by Argentine researchers: The activities and motivations of CONICET scientists. Public Underst Sci. 2010;20(1):37-47. https://doi.org/10.1177/0963662510383924

38. Chikoore L, Probets S, Fry J, Creaser C. How are UK academics engaging the public with their research? A cross-disciplinary perspective. High Educ Q. 2016;70(2):145-169. https://doi.org/10.1111/hequ.12088

39. Marcinkowski $F$, Kohring $M$, Fürst $S$, Friedrichsmeier A. Organizational influence on scientists' efforts to go public. Sci Commun. 2014;36(1):56-80. http://dx.doi.org/10.1177/1075547013494022

40. South African Department of Science and Technology (DST). South African National Survey of Research and Experimental Development - main analysis report 2014/15. Pretoria: DST; 2015.

41. Statistics South Africa (StatsSA). Mid-year population estimates. Pretoria: StatsSA; 2016

42. Ceci SJ, Williams WM. Understanding current causes of women's underrepresentation in science. Proc Natl Acad Sci USA. 2011;108(8):31573162. https://doi.org/10.1073/pnas.1014871108

43. Butler-Adam J. Africa needs more women hooked on science [homepage on the Internet]. c2015 [cited 2017 Jan 17]. Available from: http://mg.co.za/ article/2015-06-04-africa-needs-to-get-more-women-hooked-on-science

44. The Royal Society. Factors affecting science communication. London: The Royal Society; 2006.

45. Crettaz von Roten F, Goastellec G. Understanding academics' popular science publishing: Institution culture and management style effects. JNGS. 2015;13(2):15-29.

46. Dunwoody S, Brossard D, Dudo A. Socialization or rewards? Predicting US scientist-media interactions. Journalism Mass Comm. 2009;86(2):299-314. https://doi.org/10.1177/107769900908600203

47. Entradas M, Bauer M. Mobilisation for public engagement: Benchmarking the practices of research institutes. Public Underst Sci. 2016;26(7):771-788. https://doi.org/10.1177/0963662516633834

48. NeresiniF, Bucchi M. Which indicators for the new public engagementactivities? An exploratory study of European research institutions. Public Underst Sci. 2011;20(1):64-79. https://doi.org/10.1177/0963662510388363

49. Times Higher Education. World university rankings 2016 [homepage on the Internet]. c2016 [cited 2017 Mar 17]. Available from: https://www. timeshighereducation.com/world-university-rankings/2016/world-ranking
50. Peters H, Spangenberg A, Lo YY. Variations of scientist-journalist interactions across academic fields: Results of a survey of 1600 German researchers from the humanities, social sciences and hard sciences. In: Bucchi M, Trench B, editors. Quality, honesty and beauty in science and technology communication. Florence: PCST Network; 2012. p. 257-263.

51. Maze K, Barnett M, Botts EA, Stephens A, Freedman M, Guenther L. Making the case for biodiversity in South Africa: Re-framing biodiversity communications. Bothalia. 2016;46(1), Art. \#2039, 8 pages. https://doi. org/10.4102/abc.v46i1.2039

52. Clark R, Partridge T, Kuman K. Caves of the ape-men: South Africa's Cradle of Humankind World Heritage Site. Johannesburg: Wits University Press; 2010.

53. Shisana 0, Rehle T, Simbayi LC, Zuma K, Jooste S, Zungu N, et al. South African national HIV prevalence, incidence and behaviour survey. Pretoria: HSRC Press; 2014.

54. Peters HP. Scientists as public experts: Expectations and responsibilities. In: Bucchi M, Trench B, editors. Routledge handbook of public communication of science and technology. New York: Routledge; 2014. p. 70-82.

55. Berger LR, Hawks J, De Ruiter DJ, Churchill SE, Schmid P, Delezene LK, et al. Homo naledi, a new species of the genus Homo from the Dinaledi Chamber, South Africa. eLife. 2015;10(4), e09560, 35 pages. https://doi.org/10.7554/ elife.09560

56. Lents NH. Paleoanthropology wars. Skeptic Magazine. 2016;21(2):8-11.

57. McKie R. Scientist who found new human species accused of playing fast and loose with the truth [homepage on the Internet]. c2015 [cited 2017 Jan 05]. Available from: https://www.theguardian.com/science/2015/oct/25/ discovery-human-species-accused-of-rushing-errors

58. Foster G. Homo naledi: piltdown and a lesson in African prehistory [homepage on the Internet]. c2015 [cited 2017 Jan 23]. Available from: http://thoughtleader.co.za/gavinfoster/2015/11/19/naledi-piltown-and-alesson-in-african-prehistory/

59. Noakes TD. Low-carbohydrate and high-fat intake can manage obesity and associated conditions: Occasional survey. S Afr Med J. 2013;103(11):826830. https://doi.org/10.7196/SAMJ.7302

60. Naude CE, Schoonees A, Senekal M, Young T, Garner P, Volmink J. Low carbohydrate versus isoenergetic balanced diets for reducing weight and cardiovascular risk: A systematic review and meta-analysis. PLoS ONE. 2014;9(7), e100652, 30 pages. https://doi.org/10.1371/journal. pone.0100652

61. Sboros M. Tim Noakes - backlash as UCT academics say he's a danger to the public [homepage on the Internet]. c2014 [cited 2016 Dec 14]. Available from: http://www.biznews.com/health/2014/08/25/tim-noakes-backlashuct-academics-say-hes-danger-public/

62. Wild S. Enter the rockstar scientist, exit trust in science [homepage on the Internet]. c2015 [cited 2017 May 03]. Available from: https://africacheck. org/2015/10/14/comment-enter-the-rockstar-scientist-exit-peoples-trust-inscience/

63. Eliseev $A$. We need more scientific rock stars, not fewer [homepage on the Internet]. c2015 [cited 2017 May 07]. Available from: https://www. dailymaverick.co.za/article/2015-10-18-op-ed-we-need-more-scientificrock-stars-not-less/

64. Hassen T. Professor Noakes' name cleared [homepage on the Internet]. c2017 [cited 2017 May 15]. Available from: http://www.iol.co.za/southernsuburbs-tatler/news/professor-noakes-name-cleared-8837443 